\title{
On the Solidification and Structure Formation during Casting of Large Inserts in Ferritic Nodular Cast Iron
}

\begin{abstract}
ABEL TADESSE and HASSE FREDRIKSSON
The graphite nodule count and size distributions for boiling water reactor (BWR) and pressurized water reactor (PWR) inserts were investigated by taking samples at heights of 2160 and $1150 \mathrm{~mm}$, respectively. In each cross section, two locations were taken into consideration for both the microstructural and solidification modeling. The numerical solidification modeling was performed in a two-dimensional model by considering the nucleation and growth in eutectic ductile cast iron. The microstructural results reveal that the nodule size and count distribution along the cross sections are different in each location for both inserts. Finer graphite nodules appear in the thinner sections and close to the mold walls. The coarser nodules are distributed mostly in the last solidified location. The simulation result indicates that the finer nodules are related to a higher cooling rate and a lower degree of microsegregation, whereas the coarser nodules are related to a lower cooling rate and a higher degree of microsegregation. The solidification time interval and the last solidifying locations in the BWR and PWR are also different.
\end{abstract}

https://doi.org/10.1007/s11663-018-1221-z

(c) The Author(s) 2018. This article is an open access publication

\section{INTRODUCTION}

SVENSK Kärnbränslehantering AB (SKB) investigated a method to store nuclear waste material. The method consists of a $\mathrm{Cu}$ canister with an insert in ferritic nodular cast iron (NCI). The insert has a height of $5 \mathrm{~m}$ and a diameter of $1 \mathrm{~m}$ with 4 or 12 steel channel tubes inside. It is tricky to cast such a large casting with a homogeneous structure. A large number of casting tests have been performed, and to date, molds have been made in furan sand with the use of an inert atmosphere in the mold during casting. The filling time is $60 \mathrm{sec}-$ onds, which provides a $5 \mathrm{~m} \mathrm{~s}^{-1}$ streaming rate for the melt. This streaming rate causes waves and a splashing of the melt surface and a strong convection in the melt during the filling operation. The strong convection and the complex construction with steel tubes result in large variations in the cast structure. Two different types of inserts are produced: one insert has 4 steel channel tubes and another has 12 . The insert with 4 steel channel tubes is referred to as pressurized water reactor (PWR), and the insert with 12 steel tubes is named boiling water

ABEL TADESSE and HASSE FREDRIKSSON are with Materials Science and Engineering, Royal Institute of Technology (KTH), Brinellvägen 23, S-100 44 Stockholm, Sweden. Contact e-mail: attad@kth.se

Manuscript submitted January 24, 2017.

Article published online March 6, 2018. reactor (BWR). In this report, a structural analysis of a cross section of the two different inserts was performed. A computer analysis of the structure was also performed. More than 30 years of computer analyses of cast structures were used. ${ }^{[1-20]}$ In the beginning, rather simple simulations were performed. Later, more extensive programs have been developed. ${ }^{[17-20]}$ In this work, the COMSOL Multiphysics computer module for solidification was used. A new COMSOL module based on the kinetic models for the solidification of NCI was developed and combined with the solidification module for the calculation and analysis of the solidification structure. The calculations are compared and discussed in relation to the casting conditions and casting structure.

\section{SAMPLE PREPARATION}

Figure 1(a) shows a 3D sketch of the BWR insert with 12 steel channel tubes, and a cross section of the sample was investigated. The cross section was taken at a height of $2160 \mathrm{~mm}$. Similarly, Figure 1(b) shows a sketch of the PWR insert with four steel channel tubes. The cross section locations of the investigated samples are also shown in the figure. The samples were taken at a height of $1150 \mathrm{~mm}$.

Test bars from the mechanical ${ }^{[21,22]}$ tests were used for a metallographic analysis of the microstructure using scanning electron microscopy and light microscopy. The 


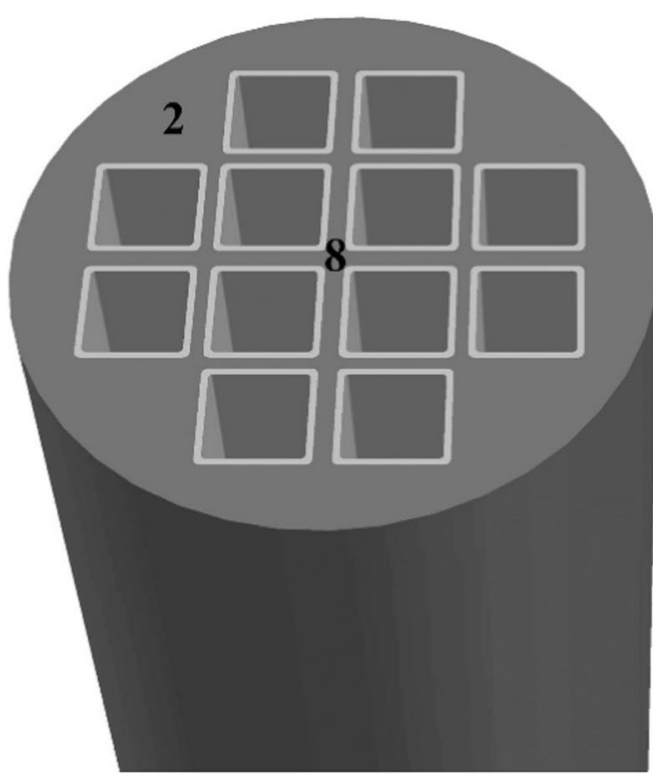

(a)

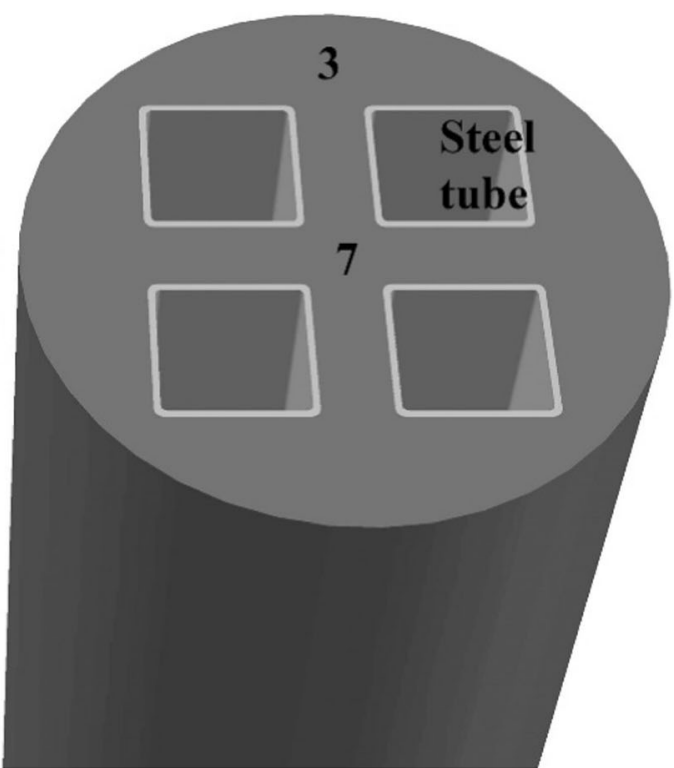

(b)

Fig. 1- $(a, b)$ The 3D cross section of BWR and PWR inserts with sampling positions where the temperature simulation and microstructural analysis were done, respectively.

microstructure was investigated on the polished surface of the samples, which were cut approximately $5 \mathrm{~mm}$ behind the fractured surface. The graphite fraction, the graphite nodule size, and its distribution were investigated. In this case, Qwin Standard software and Adobe Photoshop Elements program were used for image analysis.

The samples used for the light microscopy investigation were first analyzed without any etching. Afterwards, the samples were color etched to determine the microsegregation pattern in relation to the uneven graphite nodule distribution observed in the samples. Etching was performed using a hot alkaline solution ( $28 \mathrm{~g} \mathrm{NaOH}, 1 \mathrm{~g} \mathrm{KOH}, 200 \mathrm{~mL} \mathrm{H}_{2} \mathrm{O}$, and $4 \mathrm{~g}$ picric acid) for a time interval of approximately 12 minutes.

\section{NUMERICAL MODELS}

The simulations are based on the solidification module in the COMSOL module system. The module only considers heat transfer during cooling and solidification and neglects both the heat and mass transport due to convection. However, the heat transport is only slightly affected by convection because the mold is built by sand with a very low heat conductivity, which controls the entire temperature distribution. The mass transport can affect the alloy distribution during the solidification process; however, during the solidification of cast iron, the concentration gradient in the liquid is small, and convection has a limited effect on the element distribution. With these restrictions, the models are presented below. The material properties used in the calculations are presented in Table I.

\section{A. Heat Transfer Between the Casting and Molding Media}

In general, the solidification processes of casting metals can be described by heat transfer and phase change formulations. During the solidification of NCI, there are two basic equations that describe the heat transfer process from the molten metal to the molding media. The heat transfer includes convection, conduction, the kinetics of the liquid metal, and radiation terms, whereas the phase change is described by the phase transformation term.

In the first part of the equation, the general heat transfer process involves conduction and convection without the use of radiative heat for the molten NCI. The second part includes heat transfer in the sand mold. The core sand and steel channel tubes are assumed to exhibit continuous heat transfer without air gap formation in the solidifying melt. The heat transfer includes conduction, convection, and radiative processes from the sand mold surface to ambient air.

$$
\begin{gathered}
\rho C_{\mathrm{p}} \partial T / \partial t+\rho C_{\mathrm{p}} \boldsymbol{u} \cdot \nabla T-\nabla \cdot(k \nabla T)=\dot{Q}, \\
\left(\rho_{\mathrm{m}} C_{\mathrm{p}_{\mathrm{m}}}+\rho_{\mathrm{c}} C_{\mathrm{p}_{\mathrm{c}}}\right) \partial T / \partial t-\nabla \cdot\left(\left(k_{\mathrm{m}}+k_{\mathrm{c}}\right) \nabla T\right)=0,
\end{gathered}
$$

where $\rho$ is the density of the metal, $C_{\mathrm{p}}$ is the specific heat capacity of the metal, $\partial T / \partial t$ is the cooling rate of the molten metal, $\boldsymbol{u}$ is the velocity term of the molten metal, $k$ is the thermal conductivity of the metal, $\dot{Q}$ is the heat generation due to the phase changes in the metal, and on the left side of Eq. [2], the subscripts $m$ and $\mathrm{c}$ refer to the mold and steel channel tubes, respectively. 


\begin{tabular}{|c|c|}
\hline Parameters & Values \\
\hline Pouring Temperature $\left(T_{\mathrm{m}}\right)$ & $1593 \mathrm{~K}\left(1320^{\circ} \mathrm{C}\right)$ \\
\hline Heat of Fusion $(L)$ & $-2.27 \mathrm{E} 5 \mathrm{~J} \mathrm{~kg}^{-1}$ \\
\hline Specific Heat Capacity of Liquid $\left(C_{\mathrm{p}_{1}}\right)$ & $915.4 \mathrm{~J} \mathrm{~kg}^{-1} \mathrm{~K}^{-1}$ \\
\hline Specific Heat Capacity of Solid $\left(C_{\mathrm{p}_{\mathrm{s}}}\right)$ & $752.4 \mathrm{~J} \mathrm{~kg}^{-1} \mathrm{~K}^{-1}$ \\
\hline Undercooling Temperature $(\Delta T)$ & $T_{\text {eut }}-T_{\text {sol }}$ \\
\hline Thermal Conductivity of Liquid Cast Iron $\left(k_{1}\right)$ & $18.8 \mathrm{~W} \mathrm{~m}^{-1} \mathrm{~K}^{-1}$ \\
\hline Thermal Conductivity of Solid Cast Iron $\left(k_{\mathrm{s}}\right)$ & $22 \mathrm{~W} \mathrm{~m}^{-1} \mathrm{~K}^{-1}$ \\
\hline Density of Liquid $\left(\rho_{1}\right)$ & $6920 \mathrm{~kg} \mathrm{~m}^{-3}$ \\
\hline Density of Solid $\left(\rho_{\mathrm{s}}\right)$ & $7105 \mathrm{~kg} \mathrm{~m}^{-3}$ \\
\hline Minimum Radius of Graphite $\left(r_{0}\right)$ & $0 \mathrm{~m}$ \\
\hline Maximum Radius of Graphite for PWR $\left(r_{1}\right)$ & $0.0009 \mathrm{~m}$ \\
\hline Maximum Radius of Graphite for BWR $\left(r_{1}\right)$ & $0.0006 \mathrm{~m}$ \\
\hline Nodules Count Per Cubic Meter for PWR $(N)$ & $2.5 \mathrm{E} 5 \mathrm{~m}^{-3}$ \\
\hline Nodules Count Per Cubic Meter for BWR $(N)$ & $2.15 \mathrm{E} 6 \mathrm{~m}^{-3}$ \\
\hline Density of Steel Channel Tubes $\left(\rho_{\mathrm{c}}\right)$ & $7850 \mathrm{~kg} \mathrm{~m}^{-3}$ \\
\hline Specific Heat Capacity of Steel Channel Tubes $\left(C_{\mathrm{p}_{\mathrm{c}}}\right)$ & $475 \mathrm{~J} \mathrm{~kg}^{-1} \mathrm{~K}^{-1}$ \\
\hline Thermal Conductivity of Steel Channel Tubes $\left(k_{\mathrm{c}}\right)$ & $44.5 \mathrm{~W} \mathrm{~m}^{-1} \mathrm{~K}^{-1}$ \\
\hline Heat Transfer Coefficient of Mold-Air $\left(h_{\mathrm{w}}\right)$ & $6.8 \mathrm{~W} \mathrm{~m}^{-2} \mathrm{~K}^{-1}$ \\
\hline Emissivity of Mold Surface $(\varepsilon)$ & 0.76 \\
\hline Stefan-Boltzmann Constant $(\sigma)$ & $5.67 \mathrm{E}-8 \mathrm{~W} \mathrm{~m}^{-2} \mathrm{~K}^{-4}$ \\
\hline Partition Coefficient of $\mathrm{Si}\left(k_{\mathrm{Si}}^{\gamma / 1}, k_{\mathrm{Si}_{1}}^{\mathrm{g} / 1}\right)$ & $1.09^{[18]}, 0$ \\
\hline Partition Coefficient of $\mathrm{C}\left(k_{\mathrm{C}}^{\delta / 1}, k_{\mathrm{C}}^{\mathrm{g} / 1}\right)$ & $(0.49-0.03 \times \mathrm{Si})^{[27]}, 0$ \\
\hline
\end{tabular}

The second term on the left side of Eq. [1] will be zero $(u=0)$, since the liquid is assumed to be stationary during solidification, whereas the density, heat capacity, and heat conductivity of the molten metal will change with changes in the liquid fraction $(f)$ according to

$$
\begin{gathered}
\rho=\left(f \rho_{1} C_{\mathrm{p}_{1}}+(1-f) \rho_{\mathrm{s}} C_{\mathrm{p}_{\mathrm{s}}}\right) / C_{\mathrm{p}} \\
C_{\mathrm{p}}=f C_{\mathrm{p}_{1}}+(1-f) C_{\mathrm{p}_{\mathrm{s}}}, \\
k=f k_{1}+(1-f) k_{\mathrm{s}},
\end{gathered}
$$

where the subscripts 1 and $\mathrm{s}$ refer to the liquid and solid, respectively. The values used in Eqs. [3] through [5] are presented in Table I.

The density, thermal conductivity, and heat capacity of the sand mold and core sand are expressed in terms of the change in temperature. ${ }^{[12]}$

$$
\begin{gathered}
\rho_{\mathrm{m}}=1739-0.0509 T \\
k_{\mathrm{m}}=\left(8 \times 10^{-7}\right) T^{2}-0.0006 T+0.6612 \\
C_{\mathrm{p}_{\mathrm{m}}}=\left(3 \times 10^{-7}\right) T^{3}-0.0011 T^{2}+1.542 T+392.63 .
\end{gathered}
$$

The outer surface of the mold is assumed to be in contact with the air, and the majority of the heat released from the surface will occur via convection and radiation. The emissivity of air was used for the outer mold surface to compute the heat of radiation.

$$
\begin{aligned}
& \dot{q}_{\mathrm{c}}=h_{\mathrm{w}}\left(T_{\mathrm{air}}-T\right), \\
& \dot{q}_{\mathrm{r}}=\varepsilon \sigma\left(T_{\mathrm{air}}^{4}-T^{4}\right),
\end{aligned}
$$

where $\dot{q}_{\mathrm{c}}$ is the heat of convection from the mold surface to the surroundings, $\dot{q}_{\mathrm{r}}$ is the heat of radiation from the mold surface to the surrounding atmosphere, $T_{\text {air }}=293 \mathrm{~K}\left(25^{\circ} \mathrm{C}\right), h_{\mathrm{w}}$ is the heat transfer coefficient of the mold-air interface, $\varepsilon$ is the surface emissivity, and $\sigma$ is the Stefan-Boltzmann's constant. The values used in Eqs. [9] and [10] are presented in Table I.

Thus, by coupling Eqs. [1] and [2], the heat transfer between the molten metal and the mold can be evaluated by considering the continuous heat flow and phase changes.

\section{B. Heat Generation During the Solidification}

The solidification model is described by the phase changes, which is represented in the right-hand term in Eq. [1]. This term mainly describes the heat of solidification liberated during liquid to solid phase changes. During the computation, the model considers the fractional change in the liquid as the linear term for a temperature interval between the liquidus and solidus. However, modifications can be made to this variable during a simulation and can be found in the metallurgical model. The latent heat due to the phase changes in the NCI is approximated from a laboratory scale experimental cooling curve. This value is reasonably close to the reported values in the literature. ${ }^{[23-25]}$

$$
\dot{Q}=\rho L \mathrm{~d} f / \mathrm{d} t
$$

where $L$ is the latent heat and $\mathrm{d} f / \mathrm{d} t$ is the rate of the liquid fraction change per unit time. 


\section{METALLURGICAL MODELS}

The amount of the fraction of solid formed is controlled by the heat flux released by the temperature drop in the eutectic region. ${ }^{[2,4]}$ Thus, the fraction of the liquid can be used to describe the solidification process to the eutectic growth temperature by assuming that a certain number of nodules are formed when the solidification starts, and the growth continues according to the kinetic laws valid for the type of growth process of interest. The rate of solidification for NCI eutectic growth can be expressed by the Johnson-Mehl relation, the diffusion laws for the reaction described below and by assuming that the total number of growing units are constant during the solidification. A detailed description can be found in References 5 and 6 . The schematic phase diagram together with the eutectic cell growth and interface concentration is described in Figure 2. The Johnson-Mehl relation is as follows:

$$
\begin{gathered}
f_{\mathrm{s}}=1-\exp ^{\left(-4 \pi N r^{3} / 3\right)}, \\
f=\exp ^{\left(-4 \pi N r^{3} / 3\right)},
\end{gathered}
$$

where $f_{\mathrm{s}}$ is the fraction of the solid, $N$ is the total number of nodule counts per unit volume, and $r$ is the radius of the graphite-austenite shell. The values used in Eqs. [12] and [13] are presented in Table I.

The growth rate of graphite is controlled by the diffusion of carbon from the liquid into the graphite nodules through the austenite layer. Hence, the growth rate for graphite can be described by References 2, 4:

$$
\mathrm{d} r_{\mathrm{g}} / \mathrm{d} t=D_{\mathrm{C}}^{\gamma} V_{\mathrm{m}}^{\mathrm{g}} / V_{\mathrm{m}}^{\gamma} \frac{\left(X^{\gamma / 1}-X^{\gamma / \mathrm{g}}\right)}{\left(X^{\mathrm{g}}-X^{\gamma / \mathrm{g}}\right)},
$$

where $\mathrm{d} r_{\mathrm{g}} / \mathrm{d} t$ is the growth rate of graphite, $D_{\mathrm{C}}^{\gamma}$ represents the carbon diffusion through the austenite, and $V_{\mathrm{m}}^{\mathrm{g}}$ and $V_{\mathrm{m}}^{\gamma}$ are molar volumes of graphite and austenite, respectively.

The above equation can be related to the growth temperature according to the following relation ${ }^{[26]}$.

$$
\mathrm{d} r_{\mathrm{g}} / \mathrm{d} t=2.87 \times 10^{-11} \Delta T / r_{\mathrm{g}}
$$

where $\Delta T$ is the undercooling temperature and $r_{\mathrm{g}}$ is the radius of graphite. The values employed in Eq. [15] are presented in Table I.

By calculating the fraction of solid with the COMSOL heat transfer module and using these values in the Johnson-Mehl equation, the growth rate and size of the nodules can be calculated. By setting those values into Eq. [15], the solidification temperature is found as function of time and fraction of the solid.

Then, the radius of the graphite can be found by integrating the above equation to obtain:

$$
\begin{gathered}
r_{\mathrm{g}}=r_{0}+7.576 \times 10^{-6} \sqrt{ } \Delta T t, \\
r=2.4 r_{\mathrm{g}},
\end{gathered}
$$

where $t$ is the time and $r$ is the radius of the eutectic cell (graphite-austenite shell).

The boundary conditions taken for the graphite during the computation are as follows:

$$
\text { at } t=0, \quad \text { then } r_{\mathrm{g}}=r_{0} \quad \text { at } t=t_{\text {solid }}, \quad \text { then } r_{\mathrm{g}}=r_{1} \text {. }
$$

\section{A. Microsegregation}

If we consider a ternary alloy with $\mathrm{Fe}-\mathrm{C}-\mathrm{Si}$, then the $\mathrm{C}$ and $\mathrm{Si}$ concentrations in the melt during the eutectic reaction will be different from the concentration of these elements at the beginning of the solidification due to segregation. ${ }^{[28]}$ Hence, the concentrations of the elements in the melt can be expressed with the initial concentrations of the elements, the fraction of the solid and the fraction of each phase present in the solid fraction. For the silicon concentration, Scheil's equation is applied as follows:

$$
X_{\mathrm{Si}}^{\mathrm{l}}=X_{\mathrm{Si}}^{0 \mathrm{l}}\left(1-f_{\mathrm{s}}\right)^{-\left[\left(1-k_{\mathrm{Si}}^{\gamma / 1}\right) f_{\gamma}+\left(1-k_{\mathrm{Si}}^{\mathrm{g} /}\right) f_{\mathrm{g}}\right]},
$$

where $X_{\mathrm{Si}}^{1}$ is the concentration of $\mathrm{Si}$ in the melt at an arbitrary point during the eutectic reaction, $X_{\mathrm{Si}}^{01}$ is the initial concentration of $\mathrm{Si}$ in the melt at the start of the eutectic reaction, $f_{\gamma, \mathrm{g}}$ represents the fraction of austenite and graphite, $k_{\mathrm{Si}}^{\gamma / 1}$ is the partition coefficient of $\mathrm{Si}$ at the $\gamma / 1$ interface, and $k_{\mathrm{Si}}^{\mathrm{g} / 1}$ is the partition coefficient of $\mathrm{Si}$ at the $\mathrm{g} / \mathrm{l}$ interface.

For the carbon concentration, the lever rule is valid. The concentration of carbon in the melt for a eutectic reaction can be expressed as follows:

$$
X_{\mathrm{C}}^{1}=X_{\mathrm{C}}^{01} / 1-f_{\mathrm{s}}\left[\left(1-k_{\mathrm{C}}^{\gamma / 1}\right) f_{\gamma}+\left(1-k_{\mathrm{C}}^{\mathrm{g} / 1}\right) f_{\mathrm{g}}\right],
$$

where $X_{\mathrm{C}}^{1}$ is the concentration of $\mathrm{C}$ in the melt at an arbitrary point during the eutectic reaction, $X_{\mathrm{C}}^{01}$ is the initial concentration of $\mathrm{C}$ in the melt at the start of the eutectic reaction, $f_{\gamma, \mathrm{g}}$ represents the fraction of austenite and graphite, $k_{\mathrm{C}}^{\gamma / 1}$ is the partition coefficient of $\mathrm{C}$ at the $\gamma / 1$ interface, and $k_{\mathrm{C}}^{\mathrm{g} / 1}$ is the partition coefficient of $\mathrm{C}$ at the $\mathrm{g} / \mathrm{l}$ interface.

These two relations are used to demonstrate the segregation patterns of $\mathrm{Si}$ and $\mathrm{C}$ during the solidification process. These equations will also be used to demonstrate the segregation pattern of magnesium and oxygen and the nucleation of the magnesium oxides, which will nucleate on the graphite.

\section{COUPLING OF NUMERICAL AND METAL- LURGICAL MODELS}

The coupling of the numerical and metallurgical models was realized by considering Eqs. [1] through [17]. The simulation is performed using COMSOL Multiphysics 5.2a. ${ }^{[29]}$ The program has a built-in heat transfer module for the stationary and time-dependent models. In our case, since the simulation considers a transient solidification process, the time-dependent 

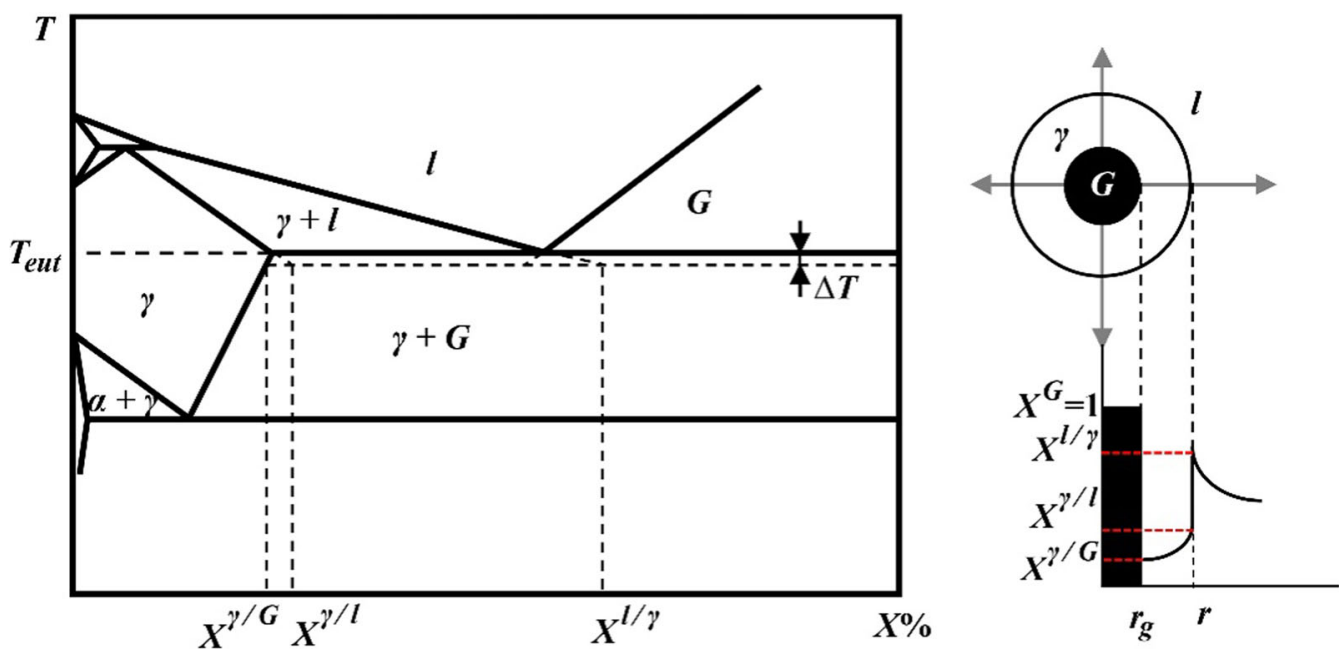

Fig. 2-The schematic phase diagram representation for the Fe-C system, along with the eutectic cell growth model. The mole fraction of carbon at different interfaces is described in both phase diagram and eutectic cell growth. $X^{\gamma / g}$ and $X^{\gamma / 1}$ are the concentration of carbon in austenite at the equilibrium interfaces $\gamma / \mathrm{g}$ and $\gamma / 1$, respectively, $X^{1 / \gamma}$ is the carbon concentration in liquid at the equilibrium interface $1 / \gamma, X^{\mathrm{g}}$ is the concentration of carbon in graphite.

Table II. Chemical Composition of the Alloy in Weight Percent

\begin{tabular}{lccccc}
\hline $\mathrm{C}$ & $\mathrm{Si}$ & $\mathrm{Mn}$ & $\mathrm{P}$ & $\mathrm{S}$ & $\mathrm{Mg}$ \\
\hline 3.54 & 2.36 & 0.17 & 0.01 & 0.01 & 0.05 \\
\hline
\end{tabular}

study was chosen. A user-defined extra fine mesh was selected during the simulation so that the computation time is at a minimum, and at the same time, the simulation is performed without a convergence problem.

\section{A. Materials selection and Thermophysical Data Used in the Simulation}

Different materials were selected from the COMSOL library for the simulation, but some modifications were made for some variables, such as the heat capacity, thermal conductivity, and density of the melt since they change with the temperature and solid fraction. Similarly, for the sand mold and core sand, the heat capacity, thermal conductivity, and density are expressed in terms of changes in temperature. The mathematical expressions for the respective terms are included in Eqs. [3] through [8].

- For the sand mold and core, the chemically bonded furan shell and molding sand were selected, respectively, from the material library, and the terms were modified.

- For the melt, ferritic ductile iron was selected from the material library, and the heat capacity, thermal conductivity, and density were modified. The chemical composition of the alloy is summarized in Table II.

- For the steel channel tubes, AISI 4340 steel was selected from the material library.

The liquidus, eutectic, and solidus temperatures were used as the boundary criteria to bound the solidification computation and estimated by considering the C:
3.5 wt pct, Si: 2.4 wt pct, and P: 0.01 wt pct contents of the alloy according to Reference 12

$$
\begin{gathered}
T_{\text {liq }}=1669-113(\mathrm{C}+0.25 \mathrm{Si}+0.5 \mathrm{P}), \\
T_{\text {eut }}=1135.1+13.89 \mathrm{Si}-2.05 \mathrm{Si}^{2}, \\
T_{\text {sol }}=1528.4-101(\mathrm{C}+0.18 \mathrm{Si}),
\end{gathered}
$$

where $T_{\text {liq }}, T_{\text {eut }}$, and $T_{\text {sol }}$ are the liquidus, eutectic and solidus temperatures, respectively.

\section{B. Assumption and Geometric Selection for the Simulation}

A 2D heat transfer module in a fluid with time dependence was selected for the simulation. The casting is symmetrical along the $X Y$ plane and only a quarter of the casting is taken for the simulation, so as minimize the computation time (Figure 3). Lines $\mathrm{AA}^{\prime}$ and $\mathrm{AB}^{\prime}$ are taken as thermally insulating boundaries; hence, there is no heat transfer in or out from these surfaces (Figure 3(a)). Arc $\mathrm{A}^{\prime} \mathrm{B}^{\prime}$ is assumed to have contact with air, and radiation and convection heat transfer are included in the computation. At arc $\mathrm{CC}^{\prime}$, the sand mold is assumed to have perfect contact with the melt; thus, any air gap that is present is neglected to simplify the model and consider a continuous heat flow from the melt to the mold and then finally into the atmosphere. Similarly, the core sand and steel channel tubes have 


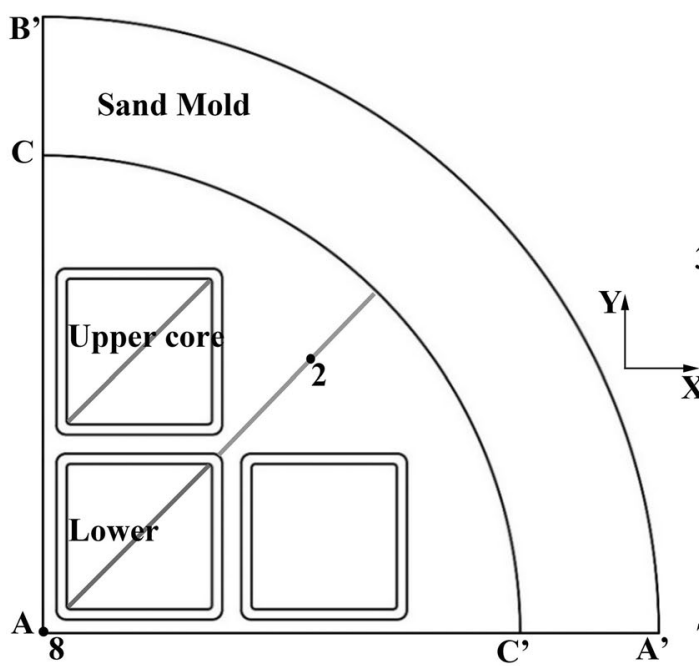

(a)

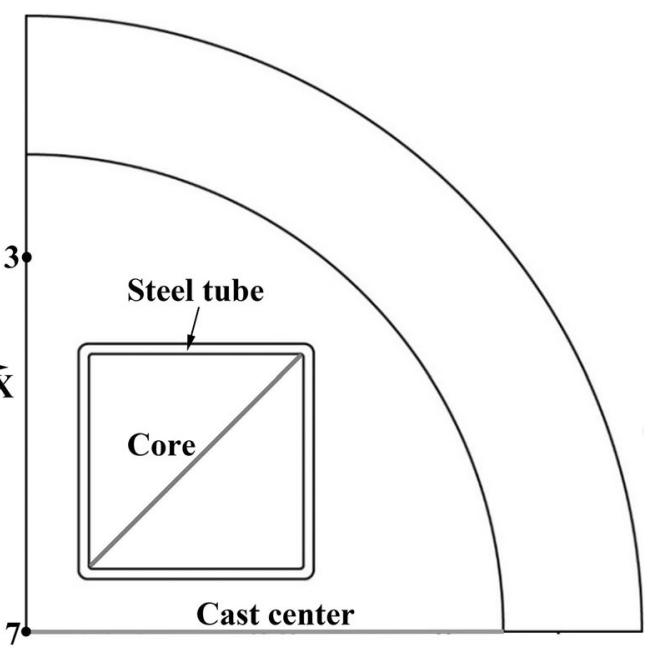

(b)

Fig. 3- $(a, b)$ Quarter of BWR and PWR insert sections, respectively. The numbers represent the point where the cooling curves are calculated. The gray lines represent the temperature line analysis positions taken from core sand and casting parts.
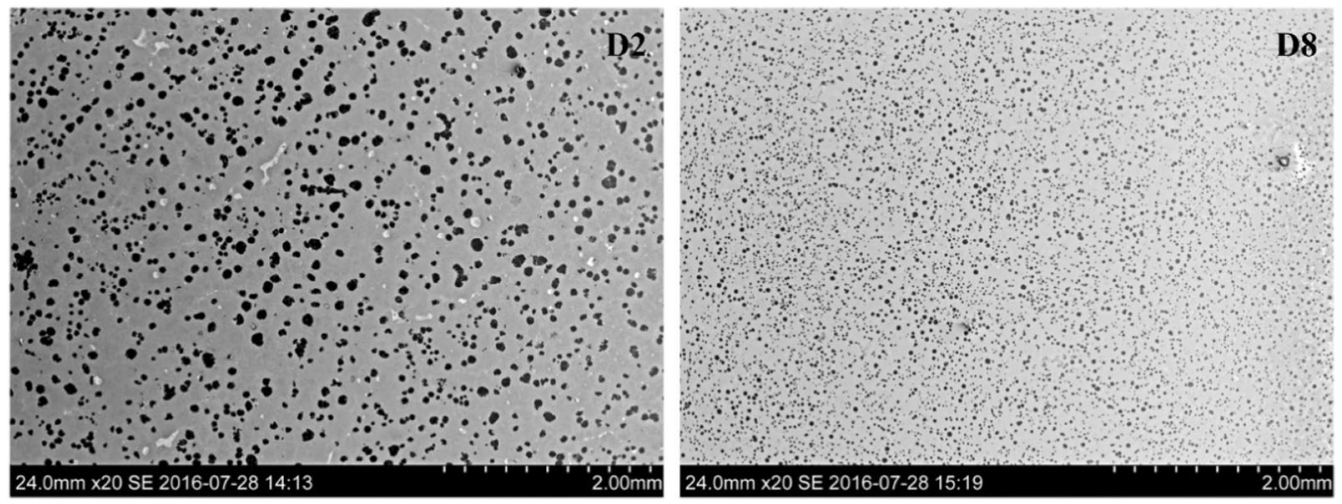

Fig. 4-Microstructure from sampling positions 2 and 8 of the BWR insert.

perfect contact with each other and with the melt, and the air gap was neglected.

Lines $\mathrm{AA}^{\prime}$ and $\mathrm{AB}^{\prime}$ in Figure 3(a) were taken as the thermally insulating boundaries to simplify the equations;

Hence,

$$
q_{\mathrm{AA}^{\prime}}=q_{\mathrm{AB}^{\prime}}=0 .
$$

The initial values and boundary conditions for the steel channel tubes, sand mold, and core sands are taken at room temperature.

$$
\text { at } t=0, \quad \text { then } T_{\mathrm{m}_{\mathrm{o}}}=T_{\mathrm{c}_{\mathrm{o}}}=T_{\mathrm{sc}_{\mathrm{o}}}=293 \mathrm{~K}\left(25^{\circ} \mathrm{C}\right) \text {. }
$$

The initial temperature of the melt is considered to be uniform all over the molten metal and taken as the pouring temperature, i.e.,

$$
\text { at } t=0, \quad \text { then } T_{\mathrm{m}}=1593 \mathrm{~K}\left(1320{ }^{\circ} \mathrm{C}\right) \text {. }
$$

Using Eqs. [13], [16], and [17] for the temperature range between $T_{\text {liq }}$ and $T_{\text {sol }}$, the fraction of liquid can be determined. Then, the density, heat capacity and conductivity can be determined using Eqs. [3] through [5]. Finally, the cooling curve for the casting can be calculated using Eqs. [1], [2], and [9] through [11]. In all the calculations, the temperature is in degrees Kelvin.

\section{RESULTS}

\section{A. Structure Analysis}

The microstructural results in the middle section of the downhill casted BWR and PWR inserts at two different locations are shown in Figures 4, 5 and 7. The microstructures reveal that the nodule size, number, and segregation patterns are different for the different locations. In the case of the BWR insert, the nodules that formed between the steel channel tubes are greater in number and closer nodule size distribution, whereas in the PWR insert, the nodule size distributions are wider in both investigated areas. This result is mainly due to the long solidification time interval and large differences in the cooling rates present at the different locations of the casting. The nodule becomes coarser at 

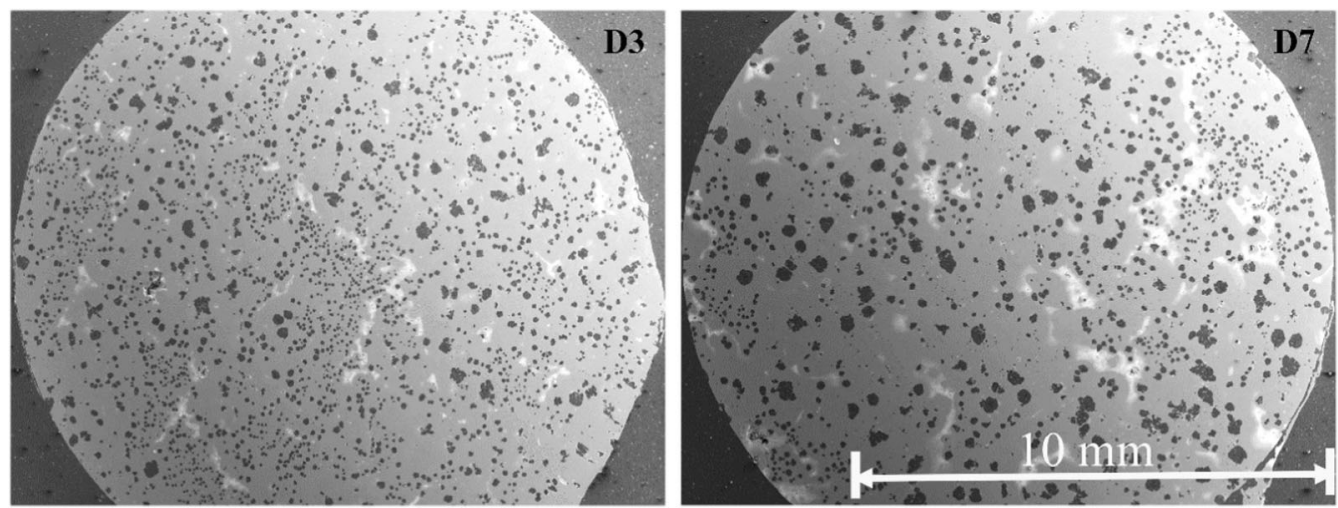

Fig. 5-Microstructure from sampling positions 3 and 7 of the PWR insert.

certain positions where the solidification time interval was longer in both the BWR and PWR inserts. The last solidifying parts in both inserts also have a greater number of coarser nodules. The pearlite fraction in the micrographs are also different in different sampling locations over the cross section.

The nodule count and size distribution along the study areas of the cross sections for the BWR and PWR are reported in Figure 6. A comparison between D2 and D8 for the BWR insert indicates that the nodule size distribution is quite wide. The measurement confirms that D2 has relatively large number of coarser graphite nodules compared to the smaller ones, whereas D8 has a large number of smaller graphite nodules compared to the coarser ones. The total number of nodule counts $\mathrm{mm}^{-2}$ for D2 and D8 are 57 and 311, respectively. The PWR insert has more fine nodules at location D3 than at D7, whereas a large number of coarse nodules observed for the reversed positions. The total number of the nodule counts $\mathrm{mm}^{-2}$ for D3 and D7 are 29 and 17 , respectively.

The etched microstructures are samples taken from the representative cross sections of the inserts (Figure 7). The shade difference reveals the pattern of $\mathrm{Si}$ segregation along the micrograph by displaying the structure over a specific color variation range. ${ }^{[30]}$ The location where the solidification occurs early is highlighted with specific colors, whereas the part that solidified late is highlighted with different one. At the same time, the Si segregation is found to be higher in the early solidified part and lower in the last solidified parts

According to the etching result, the graphite-austenite shell exhibited more clustering in parts with longer solidification intervals. In the last solidified part, shrinkage pores and carbides were formed. The graphite nodule with a longer solidification interval, which was formed during the early stages, appeared to be much coarser than the average size. These nodules are mostly found on the etched samples D2 in BWR and D7 in PWR. The two sampling locations are supposed to be the positions in the cross section that solidify last. The simulated cooling curves from the COMSOL Multiphysics simulations also confirm the hypothesis drawn from the etching results.

\section{B. Simulation Results}

\section{BWR insert}

The temperature distribution profile during solidification along a section of the BWR was simulated, and the results are presented in Figure 8(a). According to the simulation, the last solidifying part is located where the majority of the liquid is present. This observation can be seen by referring to the temperature scale bar in Figure 8, where the top of the scale bar refers to a temperature of approximately $1453 \mathrm{~K}\left(1180^{\circ} \mathrm{C}\right)$, and the bottom of the scale bar refers a temperature lower than $1373 \mathrm{~K}\left(1100{ }^{\circ} \mathrm{C}\right)$.

Similarly, the heat flux released from the BWR casting during the solidification was simulated, and the results are shown in Figure 9(a). Streamlines represent the direction of the heat flux at 5250 seconds. By considering a number of heat flux simulations at different time intervals from the start of the solidification until the molten metal completely solidified, the magnitude and direction of the heat flux change. During the early stage of the solidification, the heat flux mostly passed into the sand mold and the core sand through the steel tubes. Then, after the temperature of the core sand roughly reaches $1373 \mathrm{~K}$ $\left(1100{ }^{\circ} \mathrm{C}\right)$, the heat flux is mostly directed into the sand mold, and some of the heat goes back into some parts of the casting where the temperature drop is higher. To assess this, we chose the simulated temperature profiles for selected positions that are represented in Figure 3. These specific locations were considered because of the structural and mechanical variations observed after the tests carried out in these areas. As a result of the heat flux, a temperature increase was observed at location D8 of the BWR casting before the insert completely solidified.

According to the temperature-time curve shown in Figure 10(a), the BWR insert completely solidified after approximately 2 hours. The last solidified part of the insert is located at point 2. The two cooling curves, represented by $T_{2}$ and $T_{8}$ for the BWR insert, are completely different from one another. The cooling rate at location D8 is approximately $49 \mathrm{~K} \mathrm{~min}^{-1}$, and it is not possible to see the phase change area; however, the temperature increases roughly to $1273 \mathrm{~K}\left(1000{ }^{\circ} \mathrm{C}\right)$ after it reaches the eutectoid point.

The temperature profiles of the cast centerline and core sand, and the representative lines in the cross 


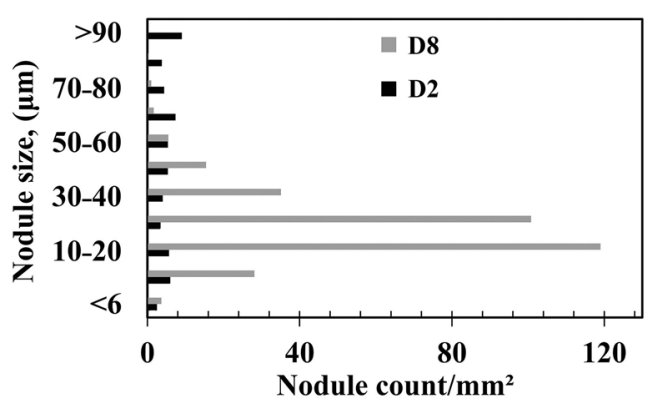

(a)

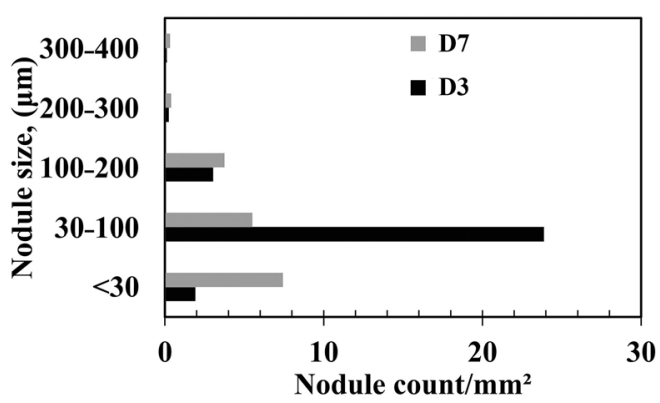

(b)

Fig. $6-(a, b)$ The nodule size and count distribution $\mathrm{mm}^{-2}$ along the study area for BWR and PWR inserts, respectively. The total investigated area for (a) $27.7 \mathrm{~mm}^{2}$ and for (b) $12.5 \mathrm{~mm}^{2}$.

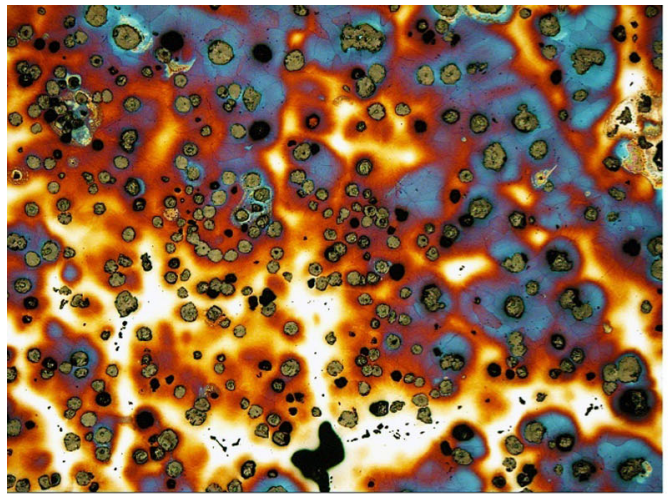

D2

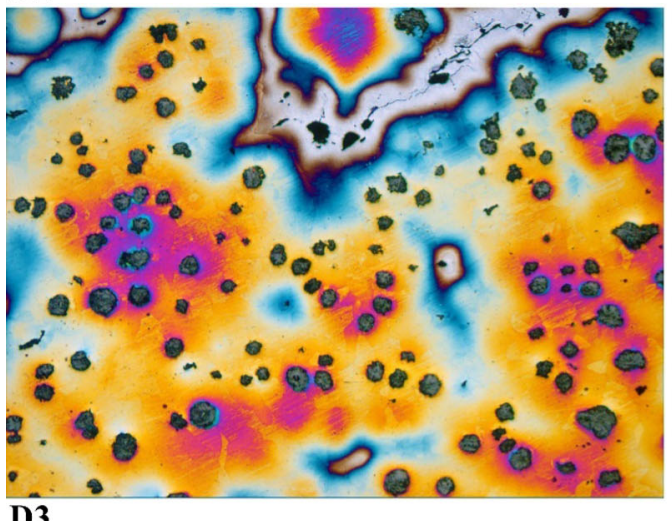

D3

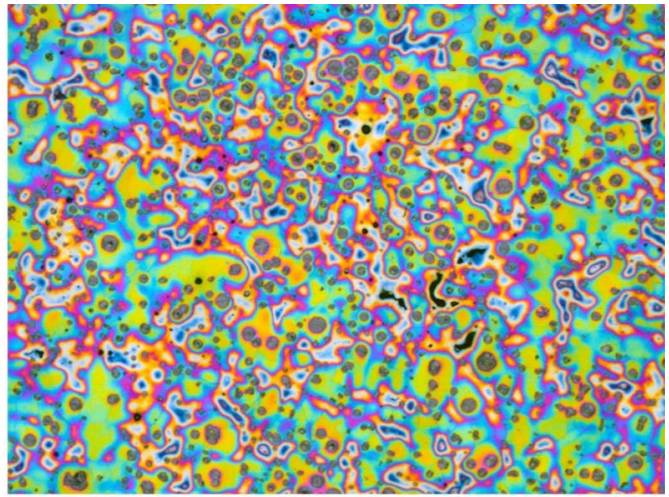

D8

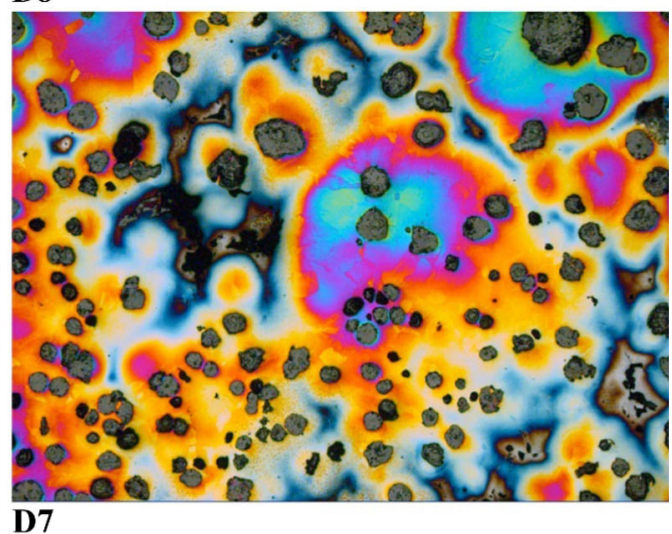

Fig. 7-Etched samples with their corresponding positions in BWR and PWR inserts. Magnification for all samples is 5 times.

section that were used in the simulation are shown in Figure 3. The different time intervals show the temperature variations (Figure 11). According to the heat source that surrounds the core sand, the upper and lower core sands of the BWR insert have different temperature profiles at different time intervals. Essentially, the lower core sand shows a lower temperature increase at opposite ends of the insert during the solidification, whereas the upper core shows a higher temperature increase on the opposite sides of the insert. According to the simulated temperature results from the line analysis, the last solidifying part is roughly at a $315-\mathrm{mm}$ arc length from the center of the cast in the BWR inserts.
The microsegregation pattern calculated using Eq. [18] is present in Figure 12(a) for the BWR insert. The black line represents the Si concentration changes in the liquid as the solid fraction increases, whereas the gray line shows the concentration changes in $\mathrm{C}$ in the liquid as the fraction of the solid approaches one. The weight percentage of $\mathrm{C}$ in the liquid increases from 3.51 to 4 as the solid fraction increases. Whereas the weight percentage of $\mathrm{Si}$ in the liquid decreases from 2.35 to 1.47 as the solid fraction increases due to microsegregation.

\section{2. $P W R$ insert}

The simulated temperature distribution profile of the PWR insert is shown in Figure 8(b). The result indicates 


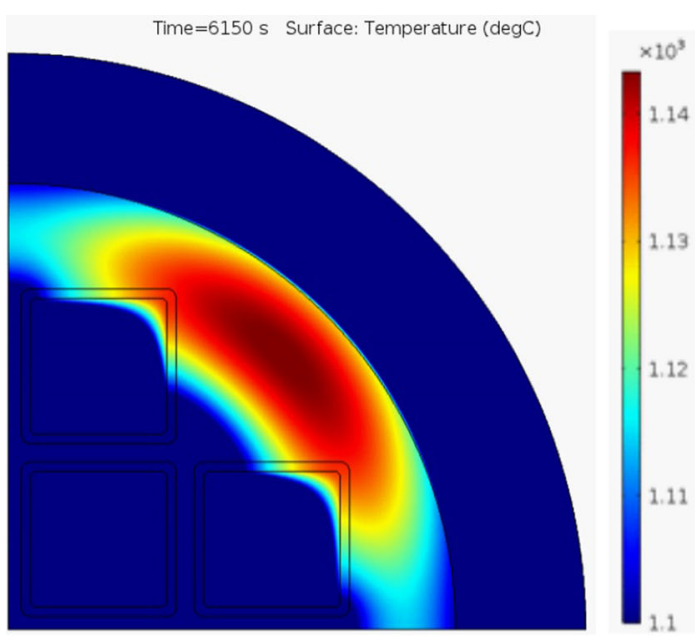

(a)

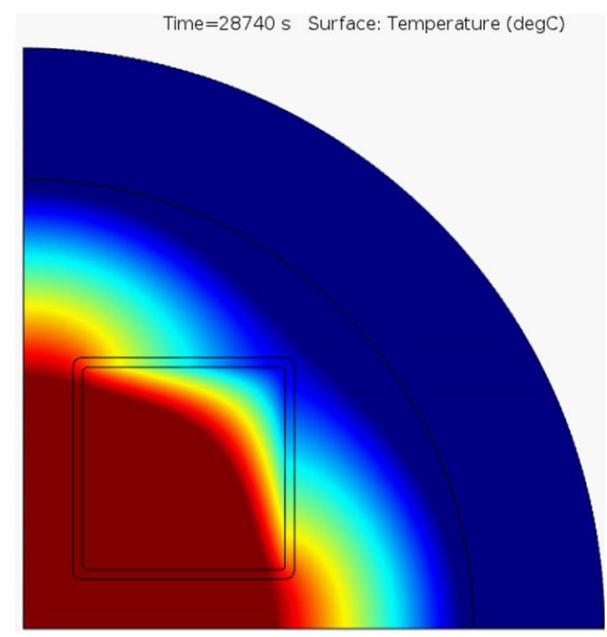

(b)

Fig. 8- $(a, b)$ Temperature profile showing the last solidifying part for BWR and PWR inserts, respectively.

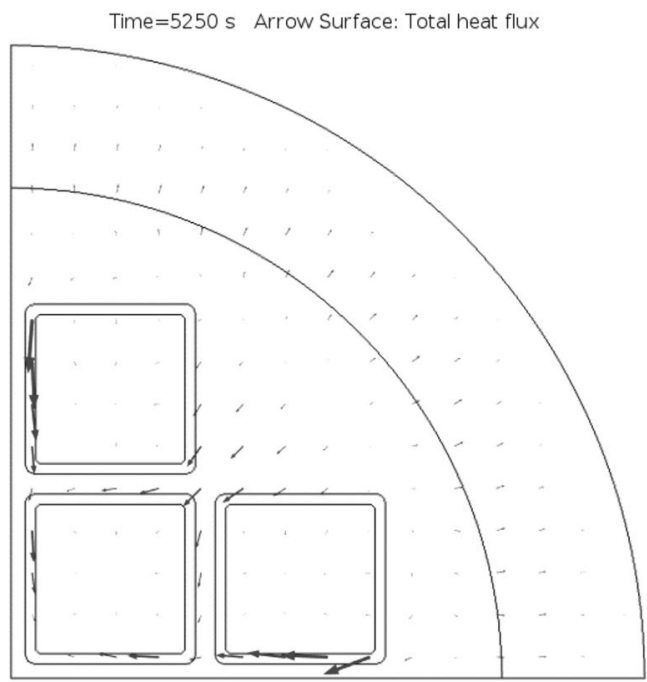

(a)

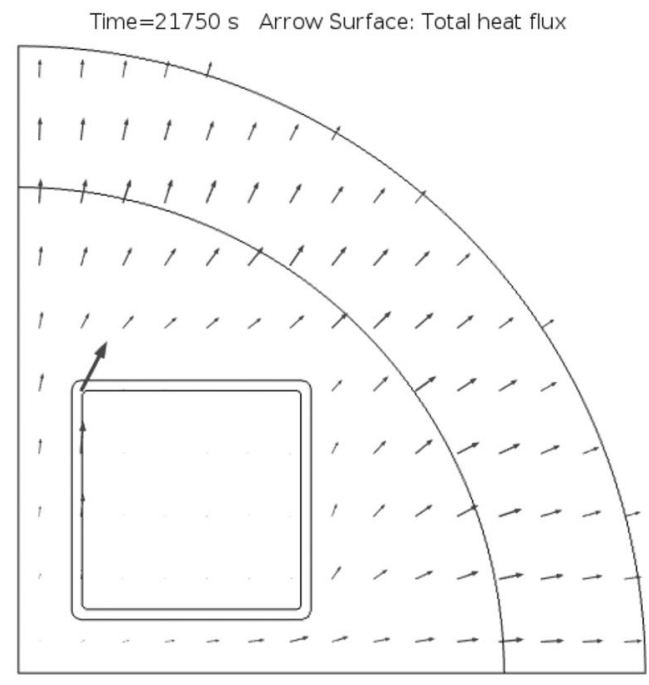

(b)

Fig. 9- $(a, b)$ Streamlines represent the heat flux liberated in the $X$ and $Y$ directions from BWR and PWR inserts, respectively.

that the last solidified part of this insert is at the center of the casting. In Figure 8, the top of the scale bar refer areas where the temperature is above the liquidus point and the bottom of the scale bar refer areas below the solidus temperature.

The heat flux is directed to the sand mold and core sand through the steel channel tubes during the early stage of the solidification. After the temperature of the core sand and steel channel tubes reaches a certain peak, the majority of the heat flux is directed towards the sand mold and then the surrounding atmosphere, as shown in Figure 9(b).

In Figure 10(b), the cooling curves of the PWR insert are reported for two locations. According to the temperature-time simulation results for locations 3 and 7, the insert is completely solidified after approximately 11 hours. The last solidified part is located at point 7 in the section. By looking at the curves for $T_{3}$ and $T_{7}$, one can identify that the cooling curves are different. $T_{7}$ has a relatively higher cooling rate than $T_{3}$ before solidification. However, after the solidification is completed, the cooling rate is relatively constant at both locations.

In Figure 11, the variation in the temperature profile with time for the core sand and casting centerline in the PWR insert is displayed. The opposite ends of the core sand temperature are essentially at the same level. The middle part of the core sand temperature increase is noticeable until it reaches a certain peak with increasing time. The temperature profile of the casting centerline indicates that the last solidifying part is at the center of the PWR insert.

The microsegregation pattern of $\mathrm{Si}$ and $\mathrm{C}$ in the liquid for the PWR insert is represented in Figure 12(b). The gray and black lines represent the concentration changes in $\mathrm{C}$ and $\mathrm{Si}$ in the liquid, respectively, as the solid fraction approaches one. The weight percentage of Si in the liquid decreases from 2.35 to 1.31 as the solid 


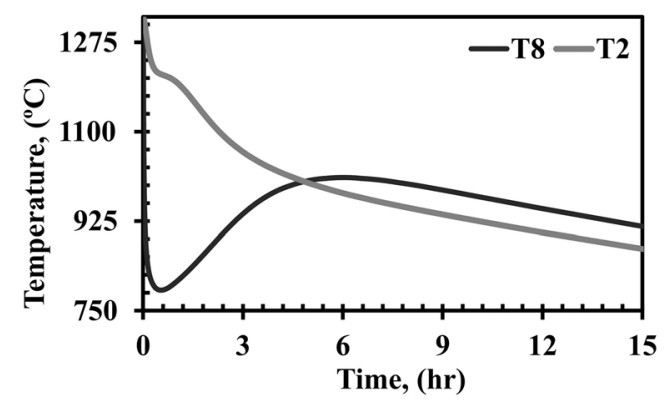

(a)

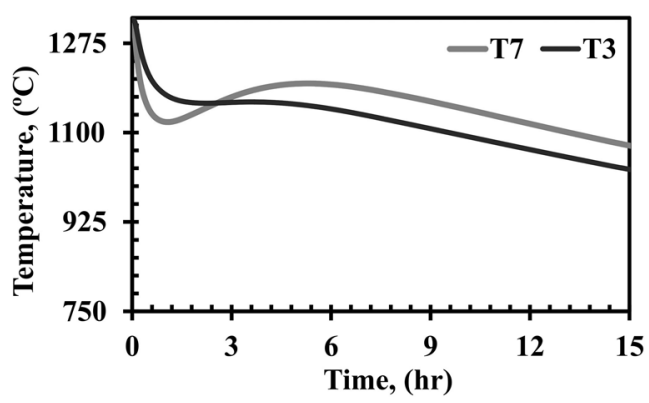

(b)

Fig. 10 - $(a, b)$ Temperature-time curves during solidification at selected locations in BWR and PWR inserts, respectively. The nodule counts used in the simulation for PWR and BWR are $2.5 \mathrm{E} 5$ and $2.15 \mathrm{E} 6 \mathrm{~m}^{-3}$, respectively.
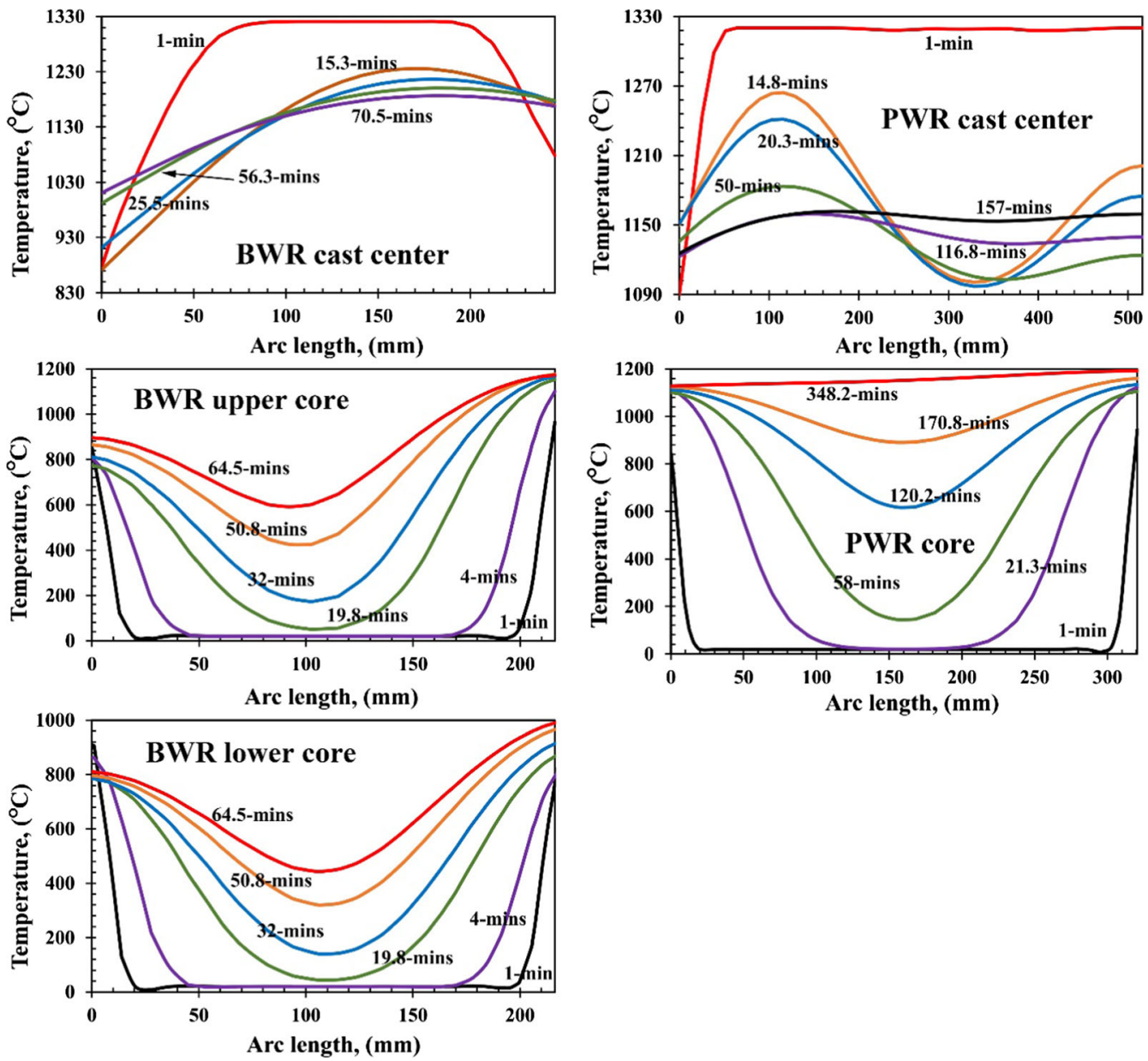

Fig. 11-Temperature variation for casting section and core sands for BWR and PWR inserts at different time intervals. The locations where the temperature variation was evaluated can be referred from Fig. 3.

fraction increases. In contrast, the weight percentage of $\mathrm{C}$ in the liquid increases from 3.51 to 3.89 with an increasing solid fraction.

\section{DISCUSSION}

In the calculations, we have assumed that all the graphite nodules are nucleated at the start of the eutectic reaction. The microstructure shows that this is not accurate, but the temperature-time curve illustrations are still reasonably correct in spite of this.

The coarseness and variations in the microstructure very much depend on the nucleation of graphite nodules. The more nodules nucleated, the finer the structure appeared. By a carefully analysis of the central part of the graphite nodules, it was found that all nodules are nucleated on an oxide or a sulfide. In most 


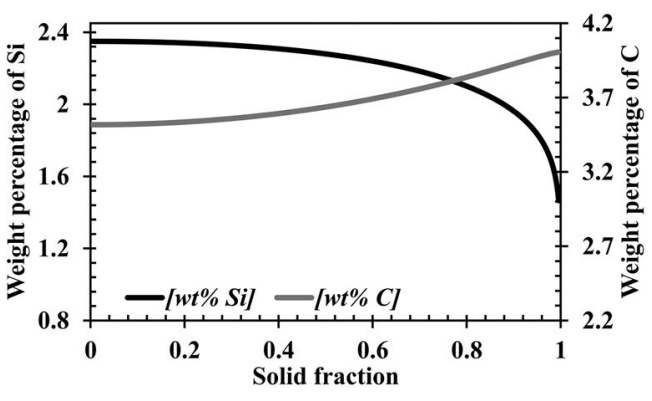

(a)

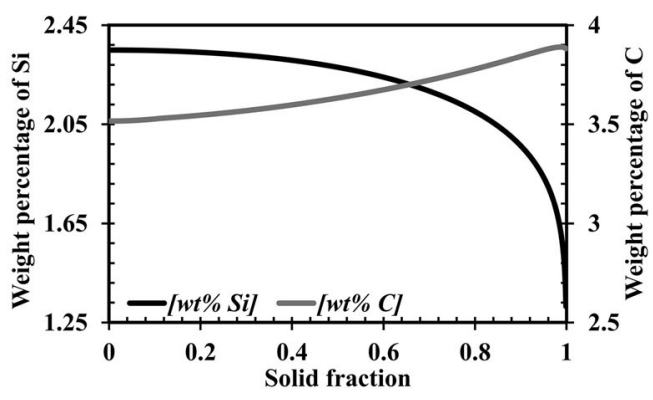

(b)

Fig. $12-(a, b)$ The microsegregation patterns, showing the weight percentage of $\mathrm{C}$ and $\mathrm{Si}$ in the liquid with increasing solid fraction, for BWR and PWR inserts, respectively.

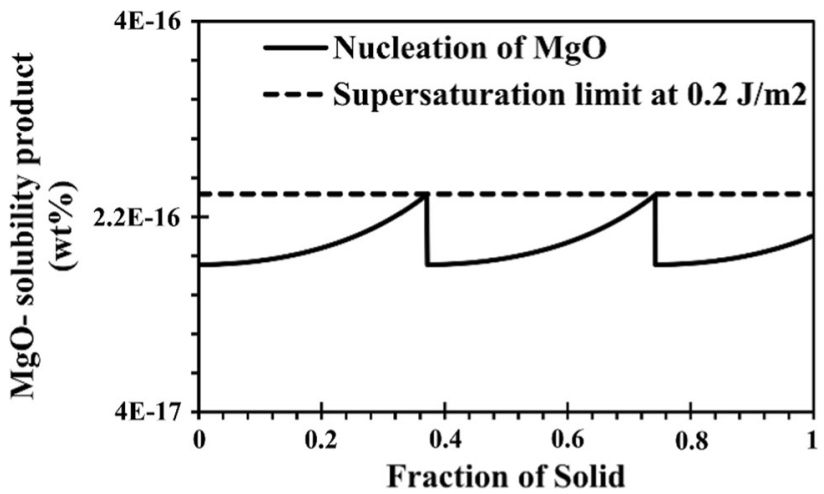

Fig. 13-The homogeneous nucleation of $\mathrm{MgO}$ at different solid fractions during solidification.

cases, the oxides were of the type $\mathrm{MgO}$. This result was also observed in a series of work by Muhmond. ${ }^{[31]}$ Muhammed observed that of least 90 pct of all graphite nodules where nucleated on $\mathrm{MgO}$ particles. As discussed in the previous paragraph, an uneven distribution and a large variation in the number of nodules were observed. These effects can be explained by a variation in the nucleation of $\mathrm{MgO}$ in the different parts of the insert.

Muhammed analyzed the effect of cooling rate on the nucleation of $\mathrm{MgO}$. At high cooling rates of the liquid, new $\mathrm{MgO}$ particles are found continuously. This new particle formation might also be the case for point 7 in Figure 4(b) in our case. The microstructure shows a greater number of small crystals compared with in any other region. This result is an indication of continuous nucleation during the cooling prior to solidification. In the other three cases, a few number of graphite nodules are formed at the start of the solidification.

The possibility of multiple $\mathrm{MgO}$ nucleation sites at different fractions of the solid during solidification is shown in Figure 13. During the solidification process, both $\mathrm{Mg}$ and $\mathrm{O}$ segregate. In the figure, the solubility product of $\mathrm{Mg}$ and $\mathrm{O}$ is presented as the solid fraction and provides the equilibrium products. The figure shows that the $\mathrm{MgO}$ particles are precipitated at certain intervals of the fraction of the solid. In the beginning, $\mathrm{MgO}$ nucleates when the solid fraction reaches approximately 0.37 during the solidification process. Then, when the solid fraction reaches approximately 0.74 , the second $\mathrm{MgO}$ nucleation occurs. One new graphite nodule is nucleated on those
Table III. Calculated Cooling Rates of the Given Locations

\begin{tabular}{lcccc}
\hline \multicolumn{5}{c}{ Cooling Rate $\left(\mathrm{K} \mathrm{min}^{-1}\right)$} \\
\hline & PWR & & & BWR \\
\cline { 3 - 5 } & $T_{3}$ & $T_{8}$ & $T_{2}$ \\
\hline 8 & 3 & 49 & 2 \\
\hline
\end{tabular}

$\mathrm{MgO}$ particles. This nucleation process explains the observations of large number of small crystals in the structure observed in sample D3.

Fine structure is observed in the first solidified regions in the central part of the PWR insert, whereas a coarser structure is observed in the last solidified parts. On the other hand, in the case of the BWR insert, fine structure is observed in the central part over the entire cross section. This result is expected because of the higher cooling rates in this region shown by the cooling curves. The nodule count $\mathrm{mm}^{-2}$ in the PWR is much lower than that in the BWR in both cross section locations. According to Figures 8 and 10, the last solidifying parts for the PWR and BWR are different. The BWR insert has a short global solidification time interval, whereas the PWR has a longer interval. Additionally, when the temperature in samples D3 and D7 increase, most likely a fewer number of graphite nodules are formed. A larger number of small nodules are formed when the temperature starts to decrease again.

The degree of the microsegregation is found to be different in the BWR and PWR inserts. According to the calculations, the BWR insert has a lower degree of microsegregation than the PWR insert due to the higher cooling rate $\left(49 \mathrm{~K} \mathrm{~min}^{-1}\right)$ in the liquidus region. On the other hand, the microsegregation calculation for $\mathrm{Si}$ agrees with the etched samples. In both cases, the $\mathrm{Si}$ concentration is less in the last solidified liquid.

In the cooling curves and Table III, the results suggest that the cooling rates at each location are different from one another for both inserts. These differences will lead to different precipitation amounts of austenite during the early stage and different solidification paths over the various cross sections.

The fraction of liquid changes with time for the BWR is much higher than that for the PWR, as shown in Figure 14. As mentioned earlier, this change will lower 

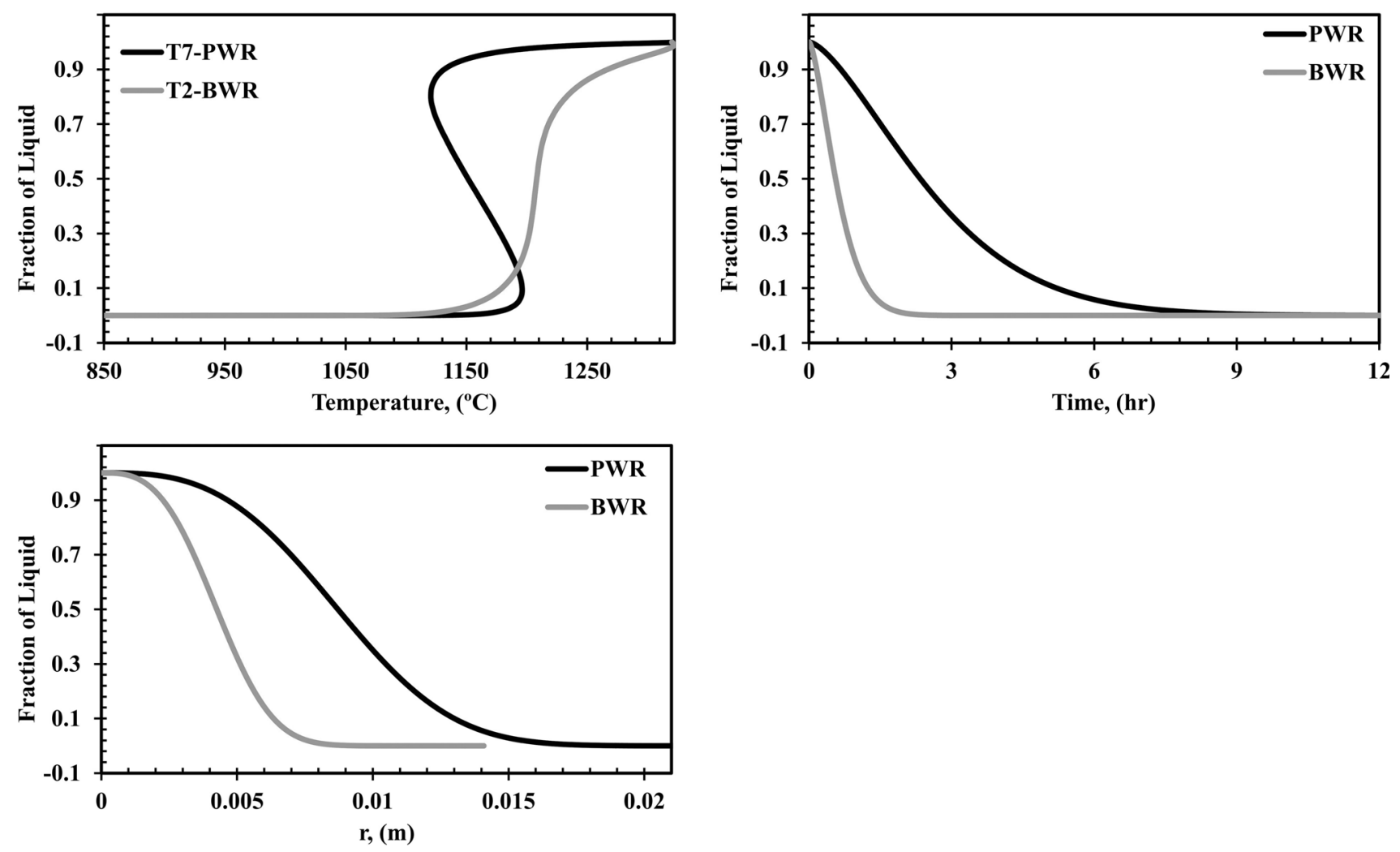

Fig. 14 -Fraction of liquid against temperature, time, and radius of the graphite-austenite shell for both PWR and BWR inserts.

the diffusion of carbon through the austenite layer in the BWR. As a result, the graphite nodule appears smaller in the BWR insert. On the other hand, the cooling rate after the solidification in the PWR is relatively higher than that in the BWR. Consequently, the fraction of pearlite formed in the final structure of the PWR insert is higher.

\section{CONCLUSION}

- There are nodule size and count variations along the different parts of the analyzed section. The nodule size variation is greater in the PWR insert, but the count $\mathrm{mm}^{-2}$ is lower and closer.

- The color-coded microstructures reveal that the pores are formed on the last solidified parts where fewer nodules are present, and carbides are precipitated.

- The simulation results suggest that fine nodule structures are related to a higher cooling rate and a lower degree of microsegregation, whereas the coarser nodules are related to lower cooling rates and a higher degree of microsegregation.

- The solidification time interval for the PWR insert is approximately five times higher than that for the BWR insert. The last solidification point of the inserts is also different along the reference sections due to the differences in the mode of the heat transfer as a result of the geometric and liquid volume differences.

- The cooling rate and the degree of microsegregation of carbon in the liquidus region are the influencing factors for the graphite nodule variations in the different cross sections.

\section{ACKNOWLEDGMENTS}

The authors would like to acknowledge SKB for financial and material supports in accomplishing this work. The authors would also acknowledge Rikard Källbom for his review and comments on the manuscript, Dr. Haji Muhammad Muhmond, and Fareed Khan for their support in microstructural sampling.

\section{OPEN ACCESS}

This article is distributed under the terms of the Creative Commons Attribution 4.0 International License (http://creativecommons.org/licenses/by/4.0/), which permits unrestricted use, distribution, and reproduction in any medium, provided you give appropriate credit to the original author(s) and the source, provide a link to the Creative Commons license, and indicate if changes were made.

\section{REFERENCES}

1. W. Oldfield: ASM Trans., 1966, vol. 59, pp. 945-60.

2. S.-E. Wetterfall, H. Fredriksson, and M. Hillert: ISIJ Int., 1972, pp. 323-33. 
3. R.D. Pehlke, R.E. Marrone, and J.O. Wilkes: Computer Simulation of Solidification, American Foundrymen's Society, Des Plaines, IL, 1976.

4. H. Fredriksson and I. Svensson: Mater. Res. Soc. Symp. Proc., 1985, vol. 34, pp. 273-84.

5. M. Rappaz: Int. Mater. Rev., 1989, vol. 34, pp. 93-123.

6. T.X. Hou, J.O. Wilkes, and R.D. Pehlke: Trans. Am. Foundrym. Soc., 1991, vol. 99, pp. 325-32.

7. J.A. Warren and W.J. Boettinger: Acta Metall. Mater., 1995, vol. A43, pp. 689-703.

8. W.J. Boettinger and J.A. Warren: Metall. Mater. Trans. A, 1996, vol. 27A, pp. 657-69.

9. M. Wessén and I.L. Svensson: Metall. Mater. Trans. A, 1996 , vol. 27A, pp. 2209-20.

10. A. Karma and W.J. Rappel: Phys. Rev. E, 1998, vol. 57, pp. 432349.

11. J. Liu and R. Elliott: J. Cryst. Growth, 1998, vol. 191, pp. 261-67.

12. D. Maijer, S.L. Cockcroft, and W. Patt: Metall. Mater. Trans. A, 1999, vol. 30A, pp. 2147-58.

13. N. Provatas, N. Goldenfeld, and J. Dantzig: Solidification 1999 , Symp. Proc. TMS Fall Meet., TMS, Warrendale, PA, 1999, pp. 151-60.

14. J.A. Dantzig: J. Met., Dec. 2000, pp. 18-21.

15. M. Plapp and A. Karma: Phys. Rev. Lett., 2000, vol. 84, pp. 1740-43.

16. I.L. Svensson and A. Diószegi: Proceedings of the Ninth International Conference on Modelling of Casting, Welding and Advanced Solidification Processes, P.R. Sahm, P.N. Hansen, J.G. Conley, eds., Aachen, Germany, 2000, pp. 102-09.

17. K.M. Pedersen, J.H. Hattel, and N. Tiedje: Acta Mater., 2006, vol. 54, pp. 5103-14.
18. F.D. Carazo, P.M. Dardati, D.J. Celentano, and L.A. Godoy: Metall. Mater. Trans. B, 2012, vol. 43B, pp. 1579-95.

19. M. Zhu, L. Zhang, H. Zhao, and D. Stefanescu: Acta Mater., 2015, vol. 84, pp. 413-25.

20. F.D. Carazo, P.M. Dardati, D.J. Celentano, and L.A. Godoy: Metall. Mater. Trans. A, 2016, vol. 47A, pp. 2625-41.

21. M. Wihed: SKBdoc 1467448 ver 1.0, Svensk Kärnbränslehantering AB, Sweden, SE, 2015.

22. M. Wihed:, SKBdoc 1526911 ver 1.0, Svensk Kärnbränslehantering AB, Sweden, SE, 2016.

23. D. Stefanescu: Mater. Res. Soc. Symp. Proc., 1985, vol. 34, pp. 151-62.

24. S. Chang, D. Shangguan, and D. Stefanescu: Metall. Mater. Trans. A, 1992, vol. 23A, pp. 1333-46.

25. S.M. Yoo, A. Kleine, A. Ludwig, and P.R. Sahm: Proceedings of the Eighth International Conference on Modeling of Casting, Welding and Advanced Solidification Processes, B.G. Thomas, C. Beckermann, eds., Aachen, Germany, 1998, pp. 471-78.

26. D. Stefanescu: Modeling for Casting and Solidification Processing, 1st ed., Marcel Dekker, Inc., New York, 2002, pp. 165-73.

27. W. Kapturkiewicz and A. Burbelko: Advances in the Science and Engineering of Casting Solidification: An MPMD Symposium Honoring Doru Michael Stefanescu, Wiley, San Francisco, 2015, pp. 313-20.

28. H. Fredriksson and U. Ảkerlind: Solidification and Crystallization Processing in Metals and Alloys, 1st ed., Wiley, Chichester, 2012, pp. 636-39.

29. COMSOL Multiphysics ${ }^{\circledR}$ v. 5.2a, COMSOL AB, Stockholm. www.comsol.com

30. Z. Jiyang: China Foundry, 2009, vol. 6, pp. 152-57.

31. H.M. Muhmond: On the Inoculation and Graphite Morphologies of Cast Iron, Sweden, SE 2014 